\section{Triclosan: Safe or Unsafe?}

\section{To the Editor:}

The article, "Serratia marcescens Contamination of Antiseptic Soap Containing Triclosan: Implications for Nosocomial Infection," by Barry et al reported that "Triclosan as a single ingredient is not safe for use in health care personnel handwashes, surgical scrubs, and patient preoperative preparations."1

This statement was published in the Tentative Final Monograph of the OrC Antimicrobial I panel. ${ }^{2}$ However, a more recent publication reported that "the Office of Drugs intends to recommend ... that the agency classify Triclosan in Category III for general use in OTC drug products" 3 in the amended Tentative Final Monograph yet to come. The proposal (William Gilbertson, OTC Division Director) involves an upgrading from Category II use of the ingredient in health care personnel handwashes, patient preoperative skin preparations, and surgical hand scrubs. The report continues that "data submitted by CibaGeigy (manufacturer of Triclosan) is sufficient to clear up several other safety questions." Therefore, the statement in the above referenced article is obsolete, misleading and must be corrected.

Further, the study by Barry et al identifies limitations of a specific formulated product (OR Scrub ${ }^{\star}$ ) but did not evaluate the efficacy of Triclosan itself and therefore cannot speak for the drug "active." In fact the addendum reported that the antimicrobial activity of OR Scrub ${ }^{\oplus}$ with a modified and improved vehicle had been substantially improved.

In summary, the FDA reported in 1982 on a proposed upgrading of Triclosan from Category II to Category III. Limitations of the product OR
Scrub $^{\$}$ should be attributed to that product rather than to the active ingredient Triclosan.

\section{REFERENCES}

l. Barry AM, Craven DE, Goularte TA, et al: Serratio marcescens contamination of antiseptic soap containing triclosan: Implications for nosocomial infection. Infect Control 1984; 5(9):427-430.

2. Tentative Final Monograph of the OTC antimicrobial I panel. Federal Register 1978; 43(Jan 6): $1210-1233$.

3. FDC Reports, June 7, $1982 \mathrm{~T} \& \mathrm{G}-8$.

Daniel L. Gravens Director of Marketing Vestal Laboratories Inc.

St. Louis, Missouri

\section{Hepatitis B Surface Antigen Testing}

\section{To the Editor:}

Testing of the recipients of Hepatitis $B$ surface antigen vaccination revealed that seroconversion is less than $50 \%$. Thus, less than one-half acquired immunity. The following questions have been raised now about this:

a) Should all recipients be tested for seroconversion?

b) What is the failure rate based on a large study in acquiring immunity after vaccination?

c) How many develop immunity after "additional doses" are given to those previously non-responsive recipients?

d) Based on a study in Lancet, ${ }^{1}$ an intradermal administration of onetenth the does provided a similar seroconversion: would this be a safer and a less expensive method?

e) How much scientific validity is there in explaining the failure to be immunized because the vaccine was really injected in the adipose tissue rather than the muscle?

\section{REFERENCES}

1. Zulek G, Lorbeer B, Jilg W, et al: Persistence of anti$H_{B}$ afier intradermal inoculation of reduced doses of hepatitis B vaccine. Lancet 1984; 2(8409): 983-984.

\section{Manuel H. Moraleda, MD VA Medical Center Battle Creek, Michigan}

Dr. Peter Heseltine responds to Dr. Moraleda's comments.

Your question implies that many recipients of hepatitis $B$ vaccine will experience a low antibody seroconversion rate. In the prelicensure clinical trials of the vaccine conducted by the New York Blood Bank Association and the Centers for Disease Control, seroconversion among susceptibles approached $95 \% .^{1,2}$ Only among patients with presumed immune problems (eg, dialysis patients) have rates been lower. If your question reflects your own experience, it is not unique. ${ }^{3,4}$ As of December 1984, over 90 hospitals had contacted the manufacturer to report suboptimal vaccine response, although a vaccine response closer to $70 \%$ seems more representative than the "less than $1 / 2$ " that you mention.

Two recent investigations, one by the manufacturer and the other by the Centers for Disease Control, indicate that the site of vaccine injection is important in explaining suboptimal vaccine response. ${ }^{5}$ In both surveys the response rate was significantly higher for hospitals injecting the vaccine in the arm than in those using buttock injections. In 93 hospitals reporting a poor response, the antibody seroconversion rate was $88 \%$ for persons receiving arm injections vs. $73 \%$ for those receiving buttock injections. In hospitals unaware of any problem, arm injections yielded $96 \%$ response and buttock injections $90 \%$. These dif ferences are statistically significant for both groups.

In a study of dialysis centers by the $\mathrm{CDC}$, vaccine response was $93 \%$ for those using arm injections and $82 \%$ 